\title{
Guest Editorial: International Space Science Institute (ISSI) Workshop on Space-Borne Imaging Spectroscopy for Exploring the Earth's Ecosystems
}

\author{
Saskia Foerster ${ }^{1} \cdot$ Luis Guanter $^{1} \cdot$ Teodolina Lopez $^{2}$ - José Moreno ${ }^{3} \cdot$ Michael Rast $^{4}$. \\ Michael E. Schaepman ${ }^{5}$
}

Received: 1 February 2019 / Accepted: 6 February 2019 / Published online: 25 March 2019

(c) Springer Nature B.V. 2019

Earth's terrestrial and aquatic ecosystems are undergoing accelerated changes as a consequence of climate change, inadequate land use and many other processes, including feedback mechanisms. In the coming decades, the world's increasing population and living standards will prompt a further increase in our demand for global food and water resources. Likewise, the increasing demand of the world's growing economies for resources such as energy, raw materials, water and land will remain a major driver of global change and environmental degradation. Furthermore, extreme weather conditions, hazards and pollution endanger human health, property and the environment. Our ability to address these increasingly urgent challenges very much depends on the improved detection, quantification and understanding of the relevant processes. A solid scientific foundation is required for informed decision making aimed at sustainable resources management.

During recent decades, imaging spectroscopy has proven to be a valuable source of information for quantifying and modelling Earth surface processes (Goetz et al. 1985; Green et al. 1998; Schaepman et al. 2009). As opposed to multispectral imaging systems, imaging spectrometers with narrow and contiguous spectral bands provide quantitative 'fingerprints' of those materials having diagnostic absorption features which can be observed by means of dispersive (prism or diffraction grating) optical systems. Since the 1980s, airborne imaging spectrometers such as AVIRIS (Vane et al. 1993), APEX (Schaepman et al. 2015) and others have been shown to provide accurate and quantitative information for many application fields. These range from mineral exploration, soil mapping, vegetation monitoring, mapping of pollution and hazardous

Saskia Foerster

saskia.foerster@gfz-potsdam.de

1 Helmholtz Centre Potsdam, GFZ German Research Centre for Geosciences, Telegrafenberg, 14473 Potsdam, Germany

2 International Space Science Institute (ISSI), Hallerstrasse 6, 3012 Bern, Switzerland

3 Image Processing Laboratory (IPL), Parc Científic, Universitat de València, C/ Catedrático José Beltrán 2, 46980 Paterna, València, Spain

4 ESA-ESRIN, Largo Galileo Galilei 1, 00044 Frascati, Italy

5 Remote Sensing Laboratories (RSL), Department of Geography, University of Zurich, Winterthurerstrasse 190, 8057 Zurich, Switzerland 
materials, inland and coastal water monitoring to urban applications. Airborne imaging spectrometers have demonstrated a solid science baseline, enabling us to scale these applications to space missions. Following on from early space-borne systems such as the Hyperion imaging spectrometer aboard NASA's Earth observing mission EO-1 and ESA's compact high-resolution imaging spectrometer CHRIS aboard the PROBA satellite, there are currently various plans to deploy imaging spectrometers in space, such as the approved Italian PRISMA (Loizzo et al. 2018) and German EnMAP (Guanter et al. 2015) missions. Further, there are a number of concepts under development, such as the US surface biology and geology SBG (Green 2018a), the Israeli/Italian SHALOM (Feingersh and Ben-Dor 2015) and the ESA Copernicus CHIME (Nieke and Rast 2018) concepts. Furthermore, the International Space Station (ISS) has become home to several spectrometers targeting the Earth's surface. Examples include the hyperspectral DESIS mission by DLR and Teledyne Brown Engineering (Müller et al. 2018). The Japanese hyperspectral mission HISUI (Matsunaga et al. 2018) and the US Earth surface mineral dust source investigation mission EMIT (Green 2018b) will be deployed on the ISS in the 2020/21 timeframe.

Even though the full solar reflected spectrum from the visible to the short wavelength infrared optical range (VSWIR) has to be contiguously covered on space missions in order to address all the aforementioned scientific and operational applications, the number of visible and near-infrared systems (VNIR, suitable for many vegetation and water applications) that can be accommodated aboard small satellites and Cubesats is increasing. For these, a coarser spatial resolution and narrower swath can be compensated for by a larger number of satellites that can be deployed at a comparably low budget. On the other hand, the socalled reference missions, mainly provided by space agencies, tend to be VSWIR systems with $\sim$ tens $\mathrm{m}$ spatial sampling. These typically incorporate a spectral sampling interval between 5 and $10 \mathrm{~nm}$ and desired temporal revisit times of the order of 10-20 days.

The advent of new technologies, for instance in the area of detector development, but also in terms of satellite formations and small satellites, gives a new direction into which imaging spectroscopy from space, aircraft and possibly high-altitude platforms can be expected to evolve. In the long run, hyperspectral systems, owing to their diagnostic capacity, are expected to supersede multispectral systems. One of the challenging aspects of space-borne hyperspectral remote sensing remains the massive amount of data generated and resulting in large three-dimensional data cubes (with spectral, spatial and temporal dimensions) provided by those spectrometers. These easily outrun data rates of conventional multispectral systems, by a large factor. However, recent developments in machine learning, data compression and data analytics open new doors for the handling and analysis of huge amounts of imaging spectroscopy data.

With the growing availability of high-quality data and advances in data analysis and handling techniques, it is expected that-in the future-data from space-borne imaging spectrometers will significantly improve our knowledge of the complex processes and feedback mechanisms of the Earth system and will support many aspects of environmental management. While most satellite missions target the measurement of one or a few variables, imaging spectroscopy can provide a large range of measurements in parallel. Hence, a set of carefully balanced requirements of measured variables, and consequently of mission objectives, is needed. Therefore, a challenging task in the definition of future imaging spectroscopy missions lies in the identification and consolidation of the user and observational requirements to support environmental management and policies in various fields, including agriculture and forestry, raw materials, water resources, hazards and pollution and biodiversity. 
The papers presented in this volume are the outcome of a Workshop on 'Exploring the Earth's Ecosystems on a Global Scale: Requirements, Capabilities and Directions in Spaceborne Imaging Spectroscopy' held at the International Space Science Institute (ISSI) in Bern, Switzerland, from 21 to 25 November 2016. The overall objective of the Workshop was to provide a better and more comprehensive understanding of the observational requirements for a range of major application fields, of the capacity of space-borne imaging spectroscopy for observing terrestrial and aquatic ecosystems as well as of potential new fields where additional geo-biophysical observations and long-term monitoring from space will make a significant contribution. Furthermore, the Workshop with its international experts in the field of imaging spectroscopy provided an excellent podium on which to discuss new operational applications, as well as the requirements for future missions and associated ground segments. The Workshop discussion was organized along the main fields of vegetation biochemistry and functioning, ecosystem structure and composition, biodiversity, inland and coastal waters, ice and snow, soils, geology and minerals, natural and man-made hazards, integrated Earth system applications, agriculture, forestry and urban environments, modelling and simulation, data processing and retrievals, the synergistic use of spectroscopy and other observational approaches, in situ measurements, validation schemes and spectral libraries, science traceability and uncertainty estimates.

The papers in this volume reflect and summarize the presentations and discussions. They comprise an overview on imaging spectroscopy and its mission legacy (Rast and Painter 2019) followed by a review on the retrieval of atmospheric parameters and surface reflectance from VSWIR imaging spectroscopy data (Thompson et al. 2019). The majority of papers focus on specific application fields of space-borne imaging spectroscopy describing the state-of-the-art situation, current gaps and user and observational requirements, in addition to challenges and future directions. These application fields include soils (Chabrillat et al. 2019), inland and coastal waters (Giardino et al. 2019), natural and anthropogenic hazards (Ong et al. 2019), urban environments (van der Linden et al. 2019), vegetation biochemistry and functioning (Gamon et al. 2019), agriculture (Hank et al. 2019) and forest ecosystems (Hill et al. 2019). The volume is completed by papers on specific across-application topics of radiative transfer models, retrieval methods and the emulation of spectral databases for vegetation observation (Verrelst et al. 2019), upscaling imaging spectroscopy observations (Malenovsky et al. 2019) and the synergistic use of imaging spectroscopy along with other remote sensing observational approaches (Guanter et al. 2019).

To conclude, a topic which started as a purely experimental and research-oriented observing technology on airborne platforms increasingly assumes the character of an operational observing capacity as we move towards space-borne imaging spectroscopy missions with global frequent mapping capabilities. It can be expected that future repeated coverage of the Earth's surface with space-borne imaging spectroscopy data will bring a major advance in both the quantity and depth of information that future models and service developments can be based upon. Thus, this volume provides a broad overview of user and observational requirements, the cases for the science, the capabilities of space-borne imaging spectroscopy technology and promising avenues into a hyperspectral future.

Acknowledgements We would like to thank the International Space Science Institute (ISSI), the European Space Agency (ESA) and all contributors to the Workshop and to this issue, the referees, the Editor in Chief, Michael Rycroft, and the staff of Springer Nature involved in its production. The first author would like to acknowledge the EnMAP mission scientific preparation program funded under the DLR Space Administration with resources from the German Federal Ministry of Economic Affairs and Energy. The contribution 
of the last author is supported by the University of Zurich Research Priority Program on Global Change and Biodiversity (URPP GCB).

\section{References}

Chabrillat et al. (2019) Surv Geophys (in review)

Feingersh T, Ben-Dor E (2015) SHALOM-a commercial hyperspectral space mission. In: Qian S (ed) Optical payloads for space missions. https://doi.org/10.1002/9781118945179.ch11

Gamon et al. (2019) Surv Geophys (in review)

Giardino C, Brando VE, Gege P, Pinnel N, Hochberg E, Knaeps E, Reusen I, Doerffer R, Bresciani M, Braga F, Foerster S, Champollion N, Dekker A (2019) Imaging spectrometry of inland and coastal waters: state of the art, achievements and perspectives. Surv Geophys. https://doi.org/10.1007/s1071 2-018-9476-0

Goetz AF, Vane G, Solomon JE, Rock BN (1985) Imaging spectrometry for earth remote sensing. Science 228(4704):1147-1153. https://doi.org/10.1126/science.228.4704.1147

Green RO (2018a) Global VSWIR imaging spectroscopy and the 2017 Decadal Survey. In: IGARSS 20182018 IEEE International Geoscience and Remote Sensing Symposium, Valencia, pp 183-185. https:// doi.org/10.1109/igarss.2018.8518744

Green RO (2018b). The earth surface mineral dust source investigation (EMIT). https://hyspiri.jpl.nasa.gov/ downloads/2018_Workshop/day1/13_HyspIRI_EMIT_Overview_20180815b.pdf. Last accessed 6 Jan 2019

Green RO, Eastwood ML, Sarture CM, Chrien TG, Aronsson M, Chippendale BJ, Faust JA, Pavri BE, Chovit CJ, Solis M, Olah MR (1998) Imaging spectroscopy and the airborne visible/infrared imaging spectrometer. Remote Sens Environ 65:227-248. https://doi.org/10.1016/S0034-4257(98)00064-9

Guanter L, Kaufmann H, Segl K, Foerster S, Rogaß C, Chabrillat S, Küster T, Hollstein A, Rossner G, Chlebek C, Straif C, Fischer S, Schrader S, Storch T, Heiden U, Mueller A, Bachmann M, Mühle H, Müller R, Habermeyer M, Ohndorf A, Hill J, Buddenbaum H, Hostert P, van der Linden S, Leitão PJ, Rabe A, Doerffer R, Krasemann H, Xi H, Mauser W, Hank T, Locherer M, Rast M, Staenz K, Sang B (2015) The EnMAP spaceborne imaging spectroscopy mission for earth observation. Remote Sens 7(7):8830-8857. https://doi.org/10.3390/rs70708830

Guanter L, Brell M, Chan JC-W, Giardino C, Gomez-Dans J, Mielke C, Morsdorf F, Segl K, Yokoya N (2019) Synergies of spaceborne imaging spectroscopy with other remote sensing approaches. Surv Geophys. https://doi.org/10.1007/s10712-018-9485-z

Hank TB, Berger K, Bach H, Clevers JGPW, Gitelson A, Zarco-Tejada P, Mauser W (2019) Spaceborne imaging spectroscopy for sustainable agriculture: contributions and challenges. Surv Geophys. https:// doi.org/10.1007/s10712-018-9492-0

Hill, Buddenbaum and Townsend (2019) Surv Geophys (in review)

Loizzo R, Guarini R, Longo F, Scopa T, Formaro R, Facchinetti C and Varacalli G (2018) Prisma: the Italian hyperspectral mission. In: IGARSS 2018-2018 IEEE International Geoscience and Remote Sensing Symposium, Valencia, pp 175-178. https://doi.org/10.1109/igarss.2018.8518512

Malenovsky et al. (2019) Surv Geophys (in review)

Matsunaga T, Iwasaki A, Tsuchida S, Iwao K, Tanii J, Nakamura R, Yamamoto H, Kato S, Obata K, Kashimura O, Tanii J, Mouri K, Tachikawa T (2018) HISUI Status Toward FY2019 Launch. In: IGARSS 2018-2018 IEEE International Geoscience and Remote Sensing Symposium, Valencia, pp 160-163. https://doi.org/10.1109/igarss.2018.8518639

Müller R, Bachmann M, Alonso K, Carmona E, Cerra D, de Ios Reyes R, Gerasch B, Krawczyk H, Ziel V, Heiden U, Krutz D (2018) Processing, validation and quality control of spaceborne imaging spectroscopy data from desis mission on the ISS. In: IGARSS 2018-2018 IEEE International Geoscience and Remote Sensing Symposium, Valencia, pp 189-191. https://doi.org/10.1109/igarss.2018.8519572

Nieke J, Rast M (2018) Towards the Copernicus Hyperspectral Imaging Mission For The Environment (CHIME). In: IGARSS 2018-2018 IEEE International Geoscience and Remote Sensing Symposium, Valencia, pp 157-159. https://doi.org/10.1109/igarss.2018.8518384

Ong et al. (2019) Surv Geophys (in review)

Rast and Painter (2019) Surv Geophys (in review)

Schaepman ME, Ustin SL, Plaza AJ, Painter TH, Verrelst J, Liang S (2009) Earth system science related imaging spectroscopy—an assessment. Remote Sens Environ Supplement 1:A123-S137. https://doi. org/10.1016/j.rse.2009.03.001 
Schaepman ME, Jehle M, Hueni A, D'Odorico P, Damm A, Weyermann J, Schneider FD, Laurent V, Popp C, Seidel FC, Lenhard K, Gege P, Küchler C, Brazile J, Kohler P, De Vos L, Meuleman K, Meynart R, Schläpfer D, Kneubühler M, Itten KI (2015) Advanced radiometry measurements and Earth science applications with the Airborne Prism Experiment (APEX). Remote Sens Environ 158:207-219. https ://doi.org/10.1016/j.rse.2014.11.014

Thompson DR, Guanter L, Berk A, Gao B-C, Richter R, Schläpfer D, Thome KJ (2019) Retrieval of atmospheric parameters and surface reflectance from visible and shortwave infrared imaging spectroscopy data. Surv Geophys. https://doi.org/10.1007/s10712-018-9488-9

van der Linden S, Okujeni A, Canters F, Degerickx J, Heiden U, Hostert P, Priem F, Somers B, Thiel F (2019) Imaging spectroscopy of urban environments. Surv Geophys. https://doi.org/10.1007/s1071 2-018-9486-y

Vane G, Green RO, Chrien TG, Enmark HT, Hansen EG, Porter WM (1993) The airborne visible/infrared imaging spectrometer (AVIRIS). Remote Sens Environ 44:127-143. https://doi.org/10.1016/00344257(93)90012-M

Verrelst J, Malenovský Z, Van der Tol C, Camps-Valls G, Gastellu-Etchegorry J-P, Lewis P, North P, Moreno J (2019) Quantifying vegetation biophysical variables from imaging spectroscopy data: a review on retrieval methods. Surv Geophys 1:1. https://doi.org/10.1007/s10712-018-9478-y

Publisher's Note Springer Nature remains neutral with regard to jurisdictional claims in published maps and institutional affiliations. 